\title{
Compassionate versus consequentialist conservation
}
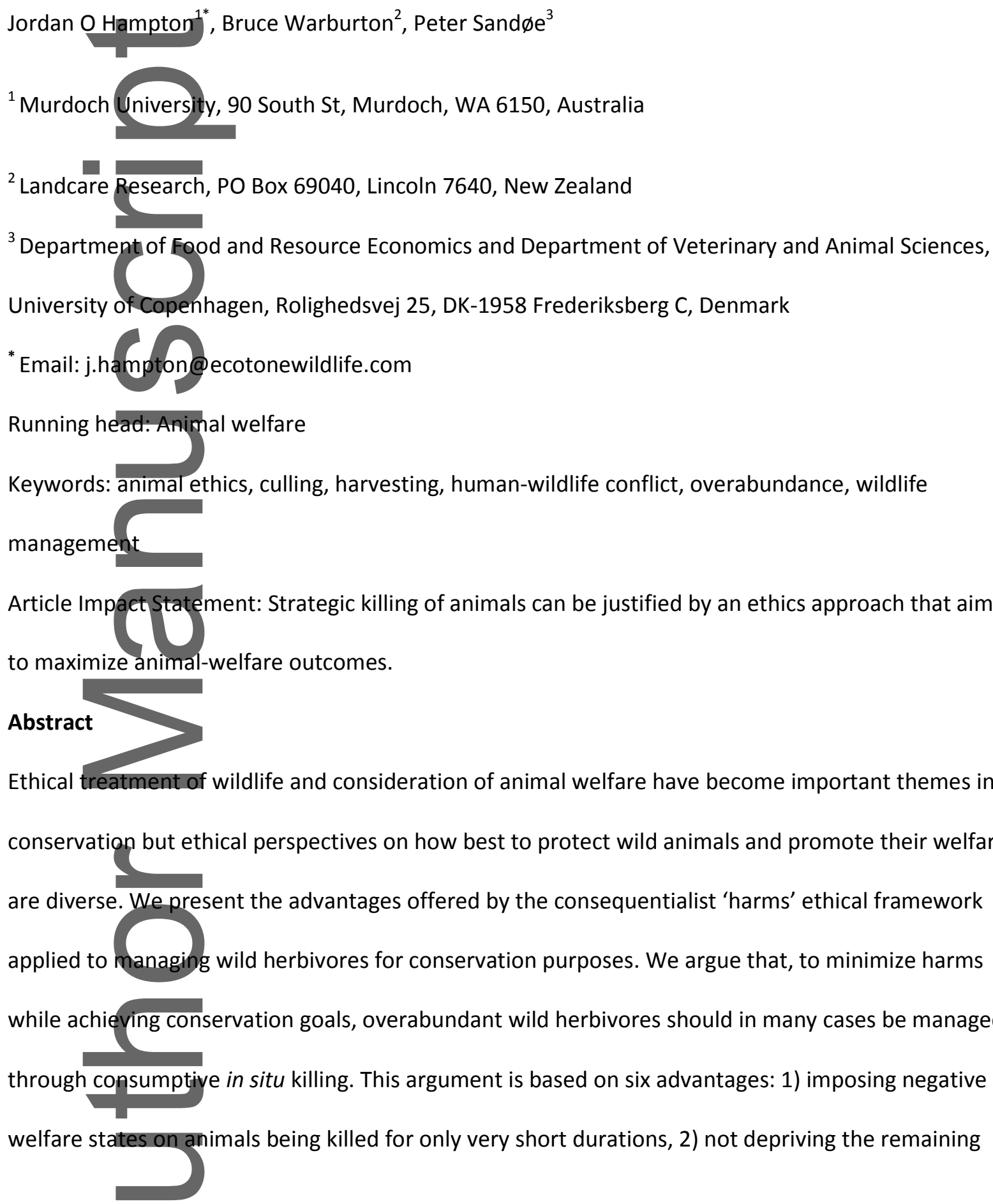

This is thuth or manuscript accepted for publication and has undergone full peer review but has not been through tho pyediting, typesetting, pagination and proofreading process, which may lead to differences between this version and the Version of Record. Please cite this article as doi: $\underline{10.1111 / \text { cobi.13249. }}$.

This article is protected by copyright. All rights reserved. 
Conservation Biology

animals of positive welfare states (e.g., linked to rearing offspring), 3) preventing overpopulation and poor welfare states facing overabundant populations (e.g., starvation), 4) preventing welfare impacts imposed on heterospecifics through resource depletion (i.e., competition), 5) harvesting meat and thereby not requiring other (agricultural) animals to be raised to supply that meat, and 6) incurring minimal costs and thereby maximizing funding available for other wildlife management and conservation priorities. Alternative ethical approaches to our consequentialist framework comprise deontology (including animal rights), and forms of virtue ethics, some of which underpin 'compassionate conservation'. These alternative ethical approaches emphasize the importance of avoiding intentional killing of animals but, if no management occurs, are likely to impose considerable unintentional harms on overabundant wildlife and indirectly harm heterospecifics through ineffective population reduction. If non-lethal ontrol is used, they are likely to deprive overabundant animals of positive welfare states and incur prohibitive economic costs. We encourage all with a stake in conservation to consider animal welfare consequentialism as an ethical approach to minimize harms to the animals under their duty of care as well as other animals that policies may affect while at the same time pursuing conservation goals.

\section{Introduction}

Concern for animal ethics plays an increasingly prominent role in discussions concerning approaches to conservation. The umbrella term 'compassionate conservation' has been used to describe ethical approaches that purport to prioritize animal welfare by avoiding intentional harm to animals,

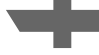
including deliberate killing of animals in routine conservation activities (Ramp 2013; Wallach et al. 2018). However, these approaches take a narrow view of animal welfare by primarily considering what is intentionally done to animals by humans, but with less focus on what happens broadly to animals as a result of anthropogenic processes. 
Conservation Biology

Here, we use the case study of herbivore management to argue that another ethical approach, welfare consequentialism, can better address animal welfare without obstructing activities required to protect biodiversity and other conservation goals. Our focus is not to make animal welfare the sole or primary goal of conservation activities, but to ensure that the best possible animal welfare outcomes are achieved while aligning with conservation priorities. There are welfare-based arguments for more interventionist approaches to animal welfare for wild animals (including intervening with natural processes such as predation; Horta 2017) but, here we focus on welfare consequences for animals resulting from anthropogenic activities.

Using the example of wild herbivores that become overabdundant due to anthropogenic changes, we compare the implications for affected animals from welfare consequentialism and alternative ethical approaches that purport to prioritize the welfare of wildlife. We argue that, when lethal control is performed professionally, and when animals are killed in situ, and in addition when they are consumed, animal welfare outcomes are in most cases superior to alternative management options.
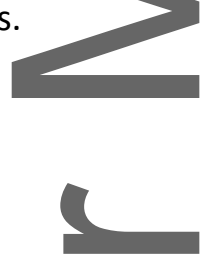

A Background to Animal Welfare, Ethics and Conservation

There are different and potentially conflicting ethical approaches to what is the right way to manage and conserve wildlife (Warburton \& Norton 2009; Gamborg et al. 2012). But recognition of this pluralism is not evident in many publications in conservation that promote one ethical position and denounce others as 'unethical' (Bekoff \& Ramp 2014).

Both wildlife management and animal welfare share similar ethical origins in that both have been traditionally underpinned by consequentialist ethics, emphasizing the importance of an action's consequences over other ethical considerations such as moral rules, character traits or rights 3

This article is protected by copyright. All rights reserved. 
Conservation Biology

(Nelson et al. 2016; Palmer et al. 2018). Under consequentialist approaches, contentious actions such as killing are considered ethically permissible if, when compared to alternative actions, they deliver a better balance of positive versus negative welfare effects (Gamborg et al. 2012; Dubois et al. 2017). These positive effects may be reduced suffering at an individual animal level (euthanasia; Wilson et al. 2015), producing reduced negative impacts on ecosystems (Howland et al. 2014), desirable outcome for humans through harvesting (Lewis et al. 1997), improvement in water quality in drinking catchments (Bennett et al. 2015), reduced vehicle collisions (DeNicola \& Williams 2008), or desirable outcomes for other animals, either agricultural or wild heterospecifics (through reduced transmission of infectious disease; Warburton \& Livingstone 2015). So far consequentialist arguments, with a focus on animal welfare, have been made to defend the use of lethal culling of carnivores in some situations (e.g., island conservation; Russell et al. 2016) but there has been less focus on the management of herbivores, with notable exceptions such as the advancement of the concept of "therapeutic hunting" (Varner 2011).

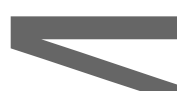

Alternative ethical approaches to welfare consequentialism have become increasingly popular in recent decades. Deontological approaches determine the moral value of an action by its conformity to a moral rule. Applications of deontology to conservation and other human activities have been prominent in opposing animal killing. Among these applications of deontology is the animal rights approach (Regan 1983) that gives priority to respect for rights, one of which is the right not to be killed.

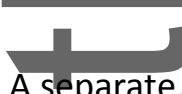

A separate, and more ancient, field of classical ethics, virtue ethics, has been invoked to support the tenets of 'compassionate conservation' (Wallach et al. 2018). Virtue ethics are focused on character traits (virtues) deemed to motivate proper conduct, rather than moral rules or guidelines (Sandter \& Cafaro 2005). Hence virtue ethics determine the moral value of an action by its manifestation of a quality of character. Virtue ethics hence has a contextual nature whereby 4

This article is protected by copyright. All rights reserved. 
Conservation Biology

practical wisdom (rather than moral rules or consideration of consequences) must be used to determine an appropriate course of action (Wallach et al. 2018). The argument that virtue ethics can support 'compassionate conservation' applies the premise that compassion is a virtue and that its application as a motivating trait towards conservation generally precludes intentionally harming wildlife.

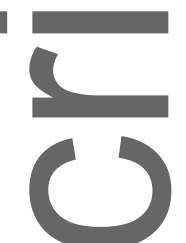

\section{Overabundant Wild Herbivores}

Populations of wild (free-ranging) herbivores are increasingly deemed unwanted or overabundant and many species are the subject of population reduction programs in post-industrial countries (Gordon 2009). Animals may be deemed to be foreign, exotic, invasive or feral (wild but having previously been domesticated) and therefore harmful to biodiversity, agriculture or human infrastructure or cultural sites. A well-known example is the culling of introduced feral camels (Camelus dromedarius) in Australia (Hampton et al. 2016) despite that group of animals representing the only wild population of the species in the world (Lundgren et al. 2017). A native animal species may also be overabundant (existing at a population density that exceeds the carrying capacity of their environment; Nugent et al. 2011). Well-known examples include overabundant white-tailed deer (Odocoileus virginianus) in north-eastern USA (VerCauteren et al. 2011) and overabundant kangaroos (Macropus spp.) in south-eastern Australia (Descovich et al. 2015).

Options for reducing the abundance of unwanted animals can be divided into lethal and non-lethal methods. Lethal methods reduce abundance by increasing animal mortality (shooting etc.) while non-lethal methods reduce animal recruitment (fertility control) or immigration (translocation, domestication or fencing). Some lethal methods involve several management stages (e.g., capture and then transport to slaughter facilities; Hampton et al. 2016) and do not kill wildlife 5

This article is protected by copyright. All rights reserved. 
Conservation Biology

in their natural environment. These methods are referred to as ex situ killing as distinct from singlestage in situ killing whereby animals are killed without prior manipulation (Pollard et al. 2002).

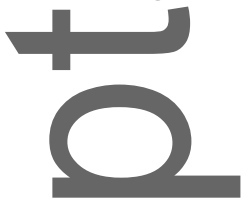

\section{Assessment of Animal Welfare}

Animal welfare in conservation has primarily focused on anthropogenic activities that intentionally and directly impose negative effects on animals (e.g., kill-trapping). There has been less awareness of activities that indirectly and/or unintentionally cause impacts (Fraser 2012). However, the animal welfare outcomes of any management program extend beyond the individual animal intentionally manipulated to those animals that are indirectly (e.g., cohort animals) or unintentionally (e.g., heterospecifics) affected. The range of these effects can be conceptualized by means of the consequentialist 'harms' framework of Fraser \& MacRae (2011) that includes consideration of processes that harm animals but may not be perpetrated deliberately or widely recognized.

Fraser \& MacRae (2011) proposed that people affect animals through four broad types of activity or harm: (1) keeping domestic or captive wild animals; (2) causing deliberate harm to wild animals through activities such as hunting; (3) causing direct but unintended harm to wild animals through infrastructure such as fencing; and (4) harming wild animals indirectly by disturbing ecological systems. Animal welfare assessments have traditionally focused on Type 1 and 2 activities with less consideration of Type 3 and 4 activities (Fraser \& MacRae 2011). Some proposed approaches for assessing animal welfare for managed wildlife consider only the intended and direct effects of management actions on targeted animals (Type 2 activities), and not how these actions may affect other animals, either unintentionally or indirectly (Beausoleil \& Mellor 2015). There is growing awareness of the importance of indirect impacts, sometimes referred to as 'invisible' harms (Finn \& Stephens 2017).

6

This article is protected by copyright. All rights reserved. 
Conservation Biology

All management options for unwanted wild herbivores will impose some harm on animals.

Animals may be harmed through imposition of negative welfare states (e.g. capture stress) or through deprivation of positive welfare states (e.g., wild animals brought into captivity; Mellor \& Beausoleil 2015) Killing itself may be considered an animal welfare impact in the way in which it may deprive animals of a future life where positive states outweigh negative ones, but it is controversial to which extent loss of life can be viewed as a welfare problem (see Kasperbauer \& Sandøe 2016 for a more full discussion of this issue). Here, we do not take a side in this debate. For the sake of not making the argument too elaborate, we will assume that the painless killing of an animal incurs no welfare cost, but our overall argument will apply even if the killing of an animal counts as a future-welfare cost that can then be compensated by the increased welfare of surviving animals.

Below we describe the harms and benefits associated with different management approaches (lethal, non-lethal, no management) for overabundant herbivores.

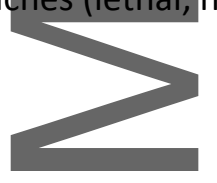

\section{Harms Arising from in situ Lethal Control}

There are no Type 1 harms as animals are not confined to captivity or domesticated. All lethal control imposes Type 2 harms on targeted animals. The magnitude of these harms may be minimized if animals are not disturbed before being killed and if the frequency of adverse animal welfare events (e.g., a protracted death or non-fatal wounding) can be minimized (Hampton \& Forsyth 2016). Animal welfare impacts are fewer for animals killed in situ than those transported or mustered prior to killing (Hampton et al. 2016), due to the absence of transport stress (Pollard et al. 2002; Grigor et al. 2004). Type 3 harms may arise through unintentional shooting of non-target species, through stress caused to cohort animals in gregarious species (Nuñez et al. 2014), or 7

This article is protected by copyright. All rights reserved. 
Conservation Biology

through orphaning of dependent juvenile animals (e.g., kangaroo 'young-at-foot'; Sharp \& McLeod 2016). Another Type 3 harm associated with shooting is poisoning of scavenging birds through use of toxic lead-based bullets (Pauli \& Buskirk 2007; Kelly et al. 2014). Type 4 harms may be imposed if population reduction is poorly regulated and reduces the abundance of the target species below a desired level (i.e., overharvesting). Type 4 harms may also occur through changed abundance and behaviour of scavengers if large numbers of culled animal carcasses are available to scavengers (Newsome \& van Eeden 2017). Type 4 harms arising from ineffective population reduction are discussed below.

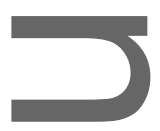

\section{Harms Arising from Non-Lethal Control}

Non-lethal management approaches have gained increasing popularity in the past decade (Ramp 2013; Wallach et al. 2018). Type 1 harms are imposed when animals are brought into captivity (Nuñez et al. 2014) or subjected to domestication and removal from their cohort, sometimes referred to as 'rehoming' (Koncel 2016). Type 2 harms are imposed by any capture or manipulation of animals in the process of administering fertility control or performing translocation. For typical fertility control programs (e.g., Tribe et al. 2014), capture stress is imposed, with such operations often requiring animals to be darted, mustered, trapped, anaesthetized, or undergo surgical procedures (Hampton et al. 2015; Palmer et al. 2018). Type 2 harms are also imposed by methods such as fertility control and fencing that deprive animals of positive welfare states such as mating and dispersal (Meltor \& Beausoleil 2015). Type 3 harms which will be caused by several non-lethal strategies include exclusion fencing (animals injured in exclusion fences; VerCauteren et al. 2006) and translocation (disease transmission to resident animals at a translocation release site; McCann et al. 2016).

8

This article is protected by copyright. All rights reserved. 


\section{Harms Associated with No Control or Ineffective Control}

Type 4 harms will be imposed by any management strategy (lethal and non-lethal) that is ineffective at reducing the abundance of an overabundant species due to ecological resource depletion. Type 4 harms resulting if population reduction is ineffective will impact on overabundant animals through loss of bodv condition, increased susceptibility to infectious diseases and parasites (Wilson et al. 2015), increasedhlikelihood of unintended anthropogenic injuries (e.g., vehicle collisions; DeNicola \& Williams 2008) and eventual starvation (Figure 1). Situations involving starvation and mass mortality of introduced wild horses are currently developing in the south-west of the USA (Masters 2017) and south-eastern Australia (Cox 2018) and provide a vivid example of Type 4 harms that may be imposed on overabundant herbivores through ineffective (or absent) population control. Another pertinent example is populations of koalas (Phascolarctos cinereus) of anthropogenic origin becoming emaciated in the absence of management actions (Wilson et al. 2015).

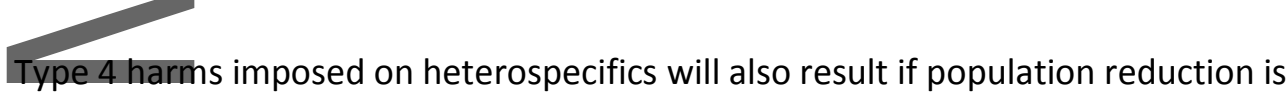

ineffective. These harms are effects of competition for food or water (Hall et al. 2018), loss of critical shelter and the increased risk of predation associated with that loss, and the longer-term degradation of critical habitat. For example, the abundance of grass-dwelling reptiles was found to be reduced in grassland areas of Australia in which kangaroo densities were high and unmanaged (Howland et al. 2014).

The magnitude of Type 4 harms resulting from any strategy will depend on the efficacy of population reduction. Lethal control methods are often, but not always, efficacious in reducing population abundance rapidly (e.g., DeNicola \& Williams 2008) as they rely on increasing mortality rather than slowing reproduction or preventing immigration. Approaches such as fertility control 
Conservation Biology

have often been shown to have low efficacy or be appropriate only for small or habituated populations (Hobbs \& Hinds 2018). Even if fertility control is effective in reducing population abundance, the interval between when management is initiated and when population reduction occurs maybe several years for long-lived species such as wild horses (Hobbs \& Hinds 2018). In the case of koala fertility control, the magnitude of this lag phase (during which Type 4 harms would continue) was estimated to be 5-10 years because of high adult female survival rates (Todd et al. 2008).
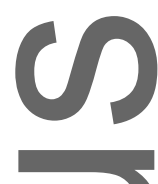

Economic and Opportunity Costs

Economic costs influence animal welfare outcomes as they determine what can feasibly be achieved and which animals or operations should be prioritized. An advantage of consumptive killing is that it improves the cost-effectiveness of management programs by minimising operational costs per animal and providing a source of income to offset operational costs (Nugent \& Choquenot 2004). For example, for control of peri-urban kangaroos in Australia, Mawson et al. (2016) reported a mean cost per animal removed of AUD \$36 for in situ harvesting. In contrast, Tribe et al. (2014) reported a mean cost per animal of AUD $\$ 104-\$ 184 /$ animal for fertility control and translocation. Cost savings may be used by management agencies to fund other conservation or animal welfare priorities (i.e., 'biodiversity offsetting'; Norton \& Warburton 2014).

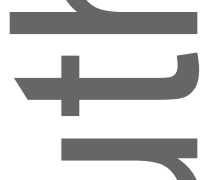

\section{Benefits Arising from Consumption of Culled Animals}

If lethal methods are used to manage unwanted wildlife, killed animals may be used (consumed) or not. Non-consumptive killing is common with animals with little commercial or cultural value. If 10

This article is protected by copyright. All rights reserved. 
Conservation Biology

consumed, meat, fur, or organs can be harvested commercially (Nugent \& Choquenot 2004),

collected for traditional/recreational use (DeNicola et al. 1997; McCann et al. 2016) or provided for scientific research (Mawson et al. 2016). Meat may be used for human consumption (Mawson et al. 2016), fed to domestic animals (e.g., pet dogs; Hercock \& Tonts 2004) or zoo animals (Harrison et al. 2006). The relevance of consumption to cumulative animal welfare impacts is that meat may be harvested from killed wildlife to substitute meat that would otherwise be derived from slaughtered livestock (Hoffman \& Cawthorn 2012). As a consequence, there may be an animal welfare benefit to consuming unwanted wildlife as the slaughter of less domestic livestock is required to supply the same quantity of meat. In view of the requirement of consequentialist ethics to maximize benefits and thereby attempt to reach the optimal harm versus benefit ratio, using products that would otherwise be wasted from the regulated lethal control of herbivores is a benefit that should be considered (Littin et al. 2004; Littin \& Mellor 2005). It needs to be made clear that the quantity of this effect is restrained by the fact that only very few people in affluent countries have access to abundant herbivores (Gordon 2009).

An additional benefit of consuming wildlife is that it may prevent harmful interference with food webs. Thus provision of large numbers of carcasses of unharvested culled animals (e.g., Forsyth et al. 2014) may constitute an indirect and unintentional Type 4 harm imposed on wildlife through supporting large populations of scavengers and predators. Possible indirect welfare consequences may include changed foraging patterns, inflated scavenger populations and starvation of these animals in the long-term if culling ceases or declines (Newsome \& van Eeden 2017; Robin 2017). These arguments have been made for readily harvestable herbivores such as peri-urban kangaroos (Fedorowytsch 2017; Gibbs 2017) and white-tailed deer (DeNicola et al. 1997; VerCauteren et al. 2011).

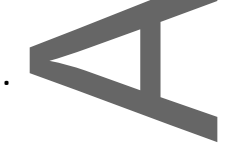

This article is protected by copyright. All rights reserved. 
Conservation Biology

\section{The Consequentialist Case for Consumptive in situ Killing}

We argue that, from a consequentialist perspective, consumptive in situ killing that is effective in reducing abundance will often yield the best animal welfare outcomes for overabundant wild herbivore management. In summary, our conclusion is based on six advantages: 1) imposing (1) negative welfare states on animals being killed for only very short durations, 2) not depriving the remaining animals of positive welfare states (e.g., linked to rearing offspring), 3) preventing overpopulation and poor welfare states in overabundant animals associated with unsustainable animal densities (e.g., starvation), 4) preventing welfare impacts imposed on other wild animals by overabundant animals through resource depletion (i.e., competition), 5) harvesting meat and thereby not requiring other (agricultural) animals to be raised to supply that meat, and 6) incurring minimal costs or generating income and thereby maximizing funding available for other animal welfare/conservation priorities.

Negative animal welfare impacts relating to lethal wildlife management are generally confined to Type 2 harms imposed on the individual animals killed, and are, provided use of professional shooting methods, mostly of short duration, with few indirect or unintentional harms imposed (Descovich et al. 2015). Such shooting methods often achieve a high frequency of immediate insensibility while achieving near-zero non-fatal wounding (Lewis et al. 1997; Hampton \& Forsyth 2016; Table 1). Regulated shooting methods observe prescriptive procedural restrictions (i.e., onty head shots; DeNicola et al. 1997; Descovich et al. 2015) and are regularly audited by animal welfare scientists (Hampton and Forsyth 2016; Table 1). We have not considered the use of more imprecise killing practices such as shotguns or archery (Nixon et al. 2001); the animal welfare impacts of such forms of recreational hunting are outside the scope of this paper. Here we are only considering the use of professional harvesting methods with validated animal welfare outcomes such as kangaroo culling (Hampton and Forsyth 2016), urban white-tail deer sharpshooting 12

This article is protected by copyright. All rights reserved. 
Conservation Biology

(DeNicola et al. 1997; DeNicola \& Williams 2008), and impala (Aepyceros melampus) cropping (Lewis et al. 1997).

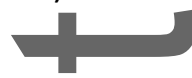

With lethal in situ methods, animals can exhibit a full range of natural behaviors

(reproduction, dispersal) and the positive experiences these provide, until the moment of death

(n)

(Palmer et al. 2018). It needs to be made clear that, for consumptive in situ killing to provide

desirable animal welfare outcomes, Type 3 harms associated with shooting must be minimized.

Orphaning of dependent juvenile animals can be minimized by deliberately killing juvenile animals as a priorty (Sharp \& McLeod 2016) and poisoning of scavenging birds can be avoided by using lead-

free bullets (McCann et al. 2016). Several conservation programs worldwide currently use consumptive in situ killing to manage overabundant wild herbivores, including kangaroos (Mawson et al. 2016) and Asian swamp buffalo (Bubalus bubalis; Albrecht et al. 2009) in Australia, African bush elephants (Loxodonta Africana) in southern Africa (Le Bel et al. 2013), roe deer (Capreolus capreolus) in Europe (Hothorn \& Müller 2010), and elk (Cervus elaphus; McCann et al. 2016) and white-tailed deer (DeNicola et al. 1997) in the USA amongst others.

\section{Alternative Ethical Positions}

Many ethical approaches, including deontology and virtue ethics, diverge from welfare consequentialism regarding the assessment of killing animals (Palmer et al. 2018) as discussed above. Alternatives to lethal control (often no management), or practices such as fertility control or guardian animals, are typically favored by these positions (Wallach et al. 2015). Regardless of their ethical origin, these seem primarily to consider animal welfare through discouraging deliberate killing (type 2 harms). We think that these approaches take too narrow a view of animal welfare by not giving sufficient weight to indirect and unintentional harms. Such approaches in our view focus 13

This article is protected by copyright. All rights reserved. 
Conservation Biology

on the plight of animals intentionally affected by human intervention at the cost of considering welfare outcomes for animals affected in a more indirect way.

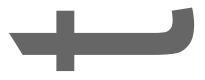

Although often unstated, welfare consequentialist approaches underpin most applications of animal welfare science (Fraser 2012; Fawcett et al. 2018), including decades of integration with conservation (Littin et al. 2004; Littin \& Mellor 2005; Dubois et al. 2017). Adoption of one of the outlined alternative ethical views would represent a considerable deviation from this focus. We recognize that consequentialism will be viewed by some as unduly cynical (Nelson et al. 2016) but it's focus on outcomes aligns with the tenets of animal welfare science and recognition of the importance of trade-offs in conservation (Leader-Williams et al. 2011).

It needs to be made clear that welfare consequentialism doesn't necessarily lead to the use of lethal methods. In some cases, adoption of welfare consequentialism may result in no management ornon-lethal approaches being used. What the view implies is that no management approaches should be ruled out, but rather what guides the adoption of a particular strategy in a particular case should be what will bring about the best aggregate animal welfare outcome. From our welfare consequentialist standpoint, we argue that deciding to do nothing (failing to act) counts as an act (Dubois et al. 2017), and like the decision to implement lethal control, it may also determine which animals will be harmed and how they will be harmed (Russell et al. 2016; Lewis et al. 2017).

Conservation decisions must be taken in light of public consultation and our intention is to ensure that such consultation is well-informed. We respect that policies of wild herbivore management may be chosen based on the premise that killing of animals should be avoided at (nearly) all cost. Our main concern is that such choices are made in a way where our welfare consequentialist view is not ruled out as 'unethical' or 'insensitive' prior to consultation. 


\section{Literature Cited}

Albrecht G, McMahon CR, Bowman DM, Bradshaw CJ. 2009. Convergence of culture, ecology, and ethics: management of feral swamp buffalo in northern Australia. Journal of Agricultural and

Environmental Ethics 22:361-378.

Beausoleil NJ, Mellor DJ. 2015. Advantages and limitations of the Five Domains model for assessing welfare impacts associated with vertebrate pest control. New Zealand Veterinary Journal.

63:37-43

Bekoff M, Ramp D. 2014. Compassion in conservation: don't be cruel to be kind. New Scietist 2974:26-27.

Cox L. 2018. Images of dead and starving brumbies prompt fresh calls for NSW cull. The Guardian. 26 October 2018.

DeNicola AJ, Weber SJ, Bridges CA, Stokes JL. 1997. Nontraditional techniques for management of overabundant deer populations. Wildlife Society Bulletin 25:496-499.

DeNicola AJ,Williams SC. 2008. Sharpshooting suburban white-tailed deer reduces deer-vehicle collisions. Human-Wildlife Conflicts 2:28-33.

Descovich K, McDonald I, Tribe A, Phillips C. 2015. A welfare assessment of methods used for re harvesting, hunting and population control of kangaroos and wallabies. Animal Welfare $24: 255-265$.

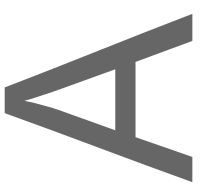

This article is protected by copyright. All rights reserved. 
Dubois S, Fenwick N, Ryan EA, Baker L, Baker SE, Beausoleil NJ, Carter S, Cartwright B, Costa F,

Draper C. 2017. International consensus principles for ethical wildlife control. Conservation L

Biology 31:753-760.

Fawcett A, Mullan S, McGreevy P. 2018. Application of Fraser's "practical" ethic in veterinary practice, and its compatibility with a "one welfare" framework. Animals: 8:109.

Fedorowytsch T. 2017. Bigger appetite for kangaroo meat needed to rein in booming roo numbers, ecologist says. ABC News. 9 September 2017.

Finn H, Stephens $N$. 2017. The invisible harm: land clearing is an issue of animal welfare. Wildlife Research 44:377-391.

Forsyth DM, Woodford L, Moloney PD, Hampton JO, Woolnough AP, Tucker M. 2014. How does a carnivore guild utilise a substantial but unpredictable anthropogenic food source? Scavenging on hunter-shot ungulate carcasses by wild dogs/dingoes, red foxes and feral cats in south-eastern Australia revealed by camera traps. PloS One 9:e97937.

Fraser D. 2012. A "practical" ethic for animals. Journal of Agricultural and Environmental Ethics $25: 721-746$.

Fraser D, MacRae AM. 2011. Four types of activities that affect animals: Implications for animal welfare science and animal ethics philosophy. Animal Welfare 20:581-590.

Gamborg C, Palmer C, Sandøe P. 2012. Ethics of wildife management and conservation: what should we try to protect? Nature Education Knowledge 3:8.

Gibbs C. 2017. Kangaroo population skyrockets in Australia, so expert says they should be eaten. New York Daily News. 11 Septmeber 2017.

This article is protected by copyright. All rights reserved. 
Gordon IJ. 2009. What is the future for wild, large herbivores in human-modified agricultural landscapes? Wildlife Biology 15:1-9.

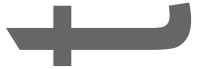

Grigor P, Cockram M, Steele W, McIntyre J, Williams C, Leushuis I, Van Reenen C. 2004. A comparison of the welfare and meat quality of veal calves slaughtered on the farm with those subjected to transportation and lairage. Livestock Production Science 91:219-228.

Hall LK, Larsen RT, Knight RN, McMillan BR. 2018. Feral horses influence both spatial and temporal patterns of water use by native ungulates in a semi-arid environment. Ecosphere 9:e02096.

Hampton JO. 2016. Animal welfare and procedure compliance for non-commercial

kangaroo shooting: Parks Victoria, 2016. Ecotone Wildlife Veterinary Services, Inverloch.

Hampton JO. 2018. Animal welfare and procedural compliance for non-commercial

kangaroo shooting: Parks Victoria, 2018. Ecotone Wildlife Veterinary Services, Inverloch.

Hampton 10, Cowled BD. 2017. Animal welfare assessment of kangaroo culling:

Australian Capital Territory, 2017. Ecotone Wildlife Veterinary Services, Inverloch.

Hampton JO,Forsyth DM. 2016. An assessment of animal welfare for the culling of peri-urban kangaroos. Wildlife Research 43:261-266.

Hampton JO, Hyndman TH, Barnes A, Collins T. 2015. Is wildlife fertility control always humane? Ánimals 5:1047-1071.

Hampton JO, Jones B, Perry AL, Miller CJ, Hart Q. 2016. Integrating animal welfare into wild herbivore management: lessons from the Australian Feral Camel Management Project. The Rangeland Journal 38:163-171.

17

This article is protected by copyright. All rights reserved. 
Hampton JO, Ward J. 2017. Animal welfare and procedure compliance for non-

commercial kangaroo shooting: Parks Victoria, 2017. Ecotone Wildlife Veterinary Services, ror Invertoch

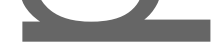

Harrison TM, Harrison SH, Rumbeiha WK, Sikarskie J, McClean M. 2006. Surveillance for selected

bacterial and toxicologic contaminants in donated carcass meat fed to carnivores. Journal of Zoo and Wildlife Medicine 37:102-107.

Hercock M, Tonts M. 2004. From the rangelands to the Ritz: Geographies of kangaroo management and trade. Geography 89:214-225.

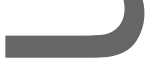

Hobbs RJ, Hinds LA. 2018. Could current fertility control methods be effective for landscape-scale management of populations of wild horses (Equus caballus) in Australia? Wildlife Research 45, $195-207$.

Hoffman L, Cawthorn D-M. 2012. What is the role and contribution of meat from wildlife in providing high quality protein for consumption? Animal Frontiers 2:40-53.

Horta O. 2017. Animal suffering in nature: the case for intervention. Environmental Ethics 39: 261279

Hothorn T, Müller J. 2010. Large-scale reduction of ungulate browsing by managed sport hunting. Forest Ecology and Management 260:1416-1423.

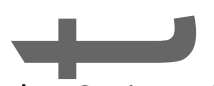

Howland B, Stojanovic D, Gordon IJ, Manning AD, Fletcher D, Lindenmayer DB. 2014. Eaten out of house and home: impacts of grazing on ground-dwelling reptiles in Australian grasslands and y woodlands. Plos One 9: e105966.

This article is protected by copyright. All rights reserved. 
Conservation Biology

Kasperbauer TJ, Sandøe P. 2016. Killing as a welfare issue. Pages 17-31 in Višak T, Garner R, editors.

The ethics of killing animals. Oxford University Press. Oxford.

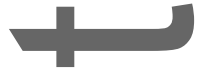

Kelly TR, Grantham J, George D, Welch A, Brandt J, Burnett LJ, Sorenson KJ, Johnson M, Poppenga R,

Moen D, Rasico J. 2014. Spatiotemporal patterns and risk factors for lead exposure in

Koncel MA. 2016. Hoofbeats from the Currituck outer banks: a study of the Corolla Wild Horse Fund Adoption Program. Journal of Applied Animal Welfare Science 19:37-48.

Le Bel S, Stansfield F, La Grange M, Taylor R. 2013. Managing local overabundance of elephants

through the supply of game meat: the case of Save Valley Conservancy, Zimbabwe. South

African Journal of Wildlife Research 43:103-119.

Leader-Wiltiams N, Adams WM, Smith RJ, editors. 2011. Trade-offs in conservation: deciding what to save.John Wiley \& Sons, Hoboken.

Lewis A, Pinchin A, Kestin S. 1997. Welfare implications of the night shooting of wild impala

(Aepyceros melampus). Animal Welfare 6:123-131.

Lewis P-M, Burns GL, Jones D. 2017. Response and responsibility: humans as apex predators and ethical actors in a changing societal environment. Food Webs 12:49-55.

Littin KE, Mellor DJ, Warburton B, Eason CT. 2004. Animal welfare and ethical issues relevant to the humane control of vertebrate pests. New Zealand Veterinary Journal 52:1-10.

Littin KE, Mellor DJ. 2005. Strategic animal welfare issues: ethical and animal welfare issues arising from the killing of wildlife for disease control and environmental reasons. Revue Scientifique et Technique-Office International des Epizooties 24:767-782.

19

This article is protected by copyright. All rights reserved. 
Lundgren EJ, Ramp D, Ripple WJ, Wallach AD. 2017. Introduced megafauna are rewilding the

Anthropocene. Ecography 41:857-866.

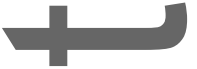

Masters B. 2017. Wild horses: the consequences of doing nothing. National Geographic. 7 February 2017.

-

Mawson PR, Hampton JO, Dooley B. 2016. Subsidized commercial harvesting for cost-effective wildlife management in urban areas: a case study with kangaroo sharpshooting. Wildlife Society Bulletin 40:251-260.

McCann BE, Whitworth W, Newman RA. 2016. Efficacy of non-lead ammunition for culling elk at Theodore Roosevelt National Park. Human-Wildlife Interactions 10:11.

Mellor D, Beausoleil N. 2015. Extending the 'Five Domains' model for animal welfare assessment to incorporate positive welfare states. Animal Welfare 24:241-253.

Nelson MP, Bruskotter JT, Vucetich JA, Chapron G. 2016. Emotions and the ethics of consequence in conservation decisions: lessons from Cecil the lion. Conservation Letters 9:302-306.

Newsome TM, van Eeden LM. 2017. The effects of food waste on wildlife and humans. Sustainability<smiles>[194Pb]</smiles><smiles>[14CH3]</smiles>

Norton DA, Warburton B. 2015. The potential for biodiversity offsetting to fund effective invasive species control. Conservation Biology 29:5-11.

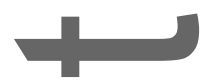

Nugent G, Choquenot D. 2004. Comparing cost-effectiveness of commercial harvesting, state-funded culling, and recreational deer hunting in New Zealand. Wildlife Society Bulletin 32:481-92.

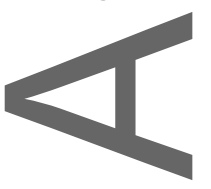

This article is protected by copyright. All rights reserved. 
Nugent G, McShea W, Parkes J, Woodley S, Waithaka J, Moro J, Gutierrez R, Azorit C, Guerrero FM, Flueck W. 2011. Policies and management of overabundant deer (native or exotic) in protected areas. Animal Production Science 51:384-389.

Nuñez CM, Adelman JS, Rubenstein DI. 2014. Sociality increases juvenile survival after a catastrophic -

event in the feral horse (Equus caballus). Behavioral Ecology 26:138-147.

Palmer C, Pedersen HG, Sandøe P. 2018. Beyond castration and culling: should we use non-surgical, pharmacological methods to control the sexual behavior and reproduction of animals? Journal of Agricultural and Environmental Ethics 31:197-218.

Pauli JN, Buskirk SW. 2007. Recreational shooting of prairie dogs: A portal for lead entering wildlife food chains. The Journal of Wildlife Management 71:103-108.

Pollard J, Littlejohn R, Asher G, Pearse A, Stevenson-Barry J, McGregor S, Manley T, Duncan S, Sutton C, Pollock K. 2002. A comparison of biochemical and meat quality variables in red deer (Cervus elaphus) following either slaughter at pasture or killing at a deer slaughter plant. Meat Science 60:85-94.

Ramp D. 2013. Bringing compassion to the ethical dilemma in killing kangaroos for conservation. Journal of Bioethical Inquiry 10:267-272.

Ramp D, Bekoff M. 2015. Compassion as a practical and evolved ethic for conservation. BioScience

\section{$65: 323-327$.}

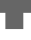

Regan T. 1983. The case for animal rights. University of California Press, Berkeley.

Robin L. 2017. Culling and care: ferals, invasives and conservation icons in Australia. Australian Zoologist 39:103-113. 
Russell JC, Jones HP, Armstrong DP, Courchamp F, Kappes PJ, Seddon PJ, Oppel S, Rauzon MJ, Cowan PE, Rocamora G. 2016. Importance of lethal control of invasive predators for island conservation. Conservation Biology 30:670-672.

Sandler R, Cafaro P. 2005. Environmental virtue ethics. Rowman \& Littlefield, 口

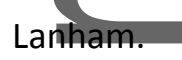

Sharp T, McLeod S. 2016. Kangaroo harvesters and the euthanasia of orphaned young-at-foot: applying the theory of planned behaviour to an animal welfare issue. Animal Welfare 25:3954.

Todd CR, Forsyth DM, Choquenot D. 2008. Modelling the effects of fertility control on koala-forest dynamics. Journal of Applied Ecology 45:568-578.

Tribe A, Hanger J, McDonald IJ, Loader J, Nottidge BJ, McKee JJ, Phillips CJ. 2014. A reproductive

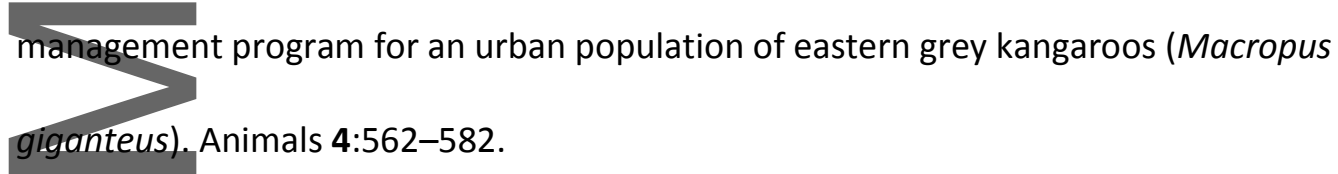

Varner G. 2011. Environmental ethics, hunting, and the place of animals. Pages 855-876

in Beauchamp T L, Frey R G, editors. The Oxford handbook of animal ethics. Oxford University Press, New York City.

VerCauteren KC, Anderson CW, Van Deelen TR, Drake D, Walter WD, Vantassel SM, Hygnstrom SE. 2011. Regulated commercial harvest to manage overabundant white-tailed deer: An idea to consider? Wildlife Society Bulletin 35:185-194.

VerCauteren KC, Lavelle MJ, Hygnstrom S. 2006. Fences and deer-damage management: a review of designs and efficacy. Wildlife Society Bulletin 34:191-200. 
Wallach AD, Bekoff M, Batavia C, Nelson MP, Ramp D. 2018. Summoning compassion to address the challenges of conservation. Conservation Biology Early view.

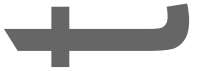

Wallach AD, Bekoff M, Nelson MP, Ramp D. 2015. Promoting predators and compassionate conservation. Conservation Biology 29:1481-1484.$$
\text { cons }
$$

(

Warburton B, Livingstone P. 2015. Managing and eradicating wildlife tuberculosis in New Zealand. New Zealand Veterinary Journal 63:77-88.

Warburton B, Norton BG. 2009. Towards a knowledge-based ethic for lethal control of nuisance wildlife. Journal of Wildlife Management 73:158-164.

Wilson DP, Craig AP, Hanger J, Timms P. 2015. The paradox of euthanizing koalas (Phascolarctos cinereus) to save populations from elimination. Journal of Wildlife Diseases 51:833-842.
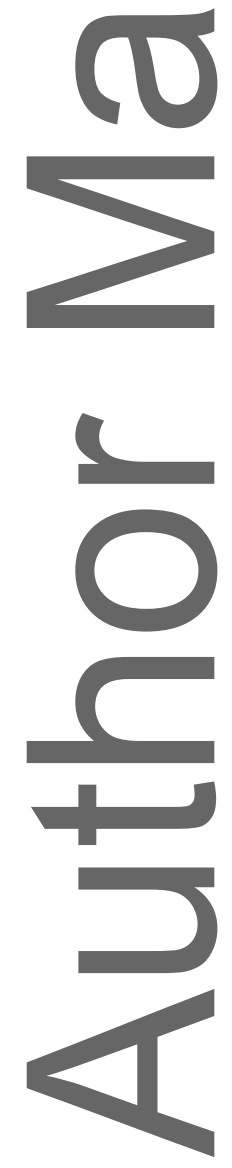

23

This article is protected by copyright. All rights reserved. 
Table 1. Frequency of key animal welfare outcomes achieved by shooting in kangaroo (Macropus spp.) culling programs.

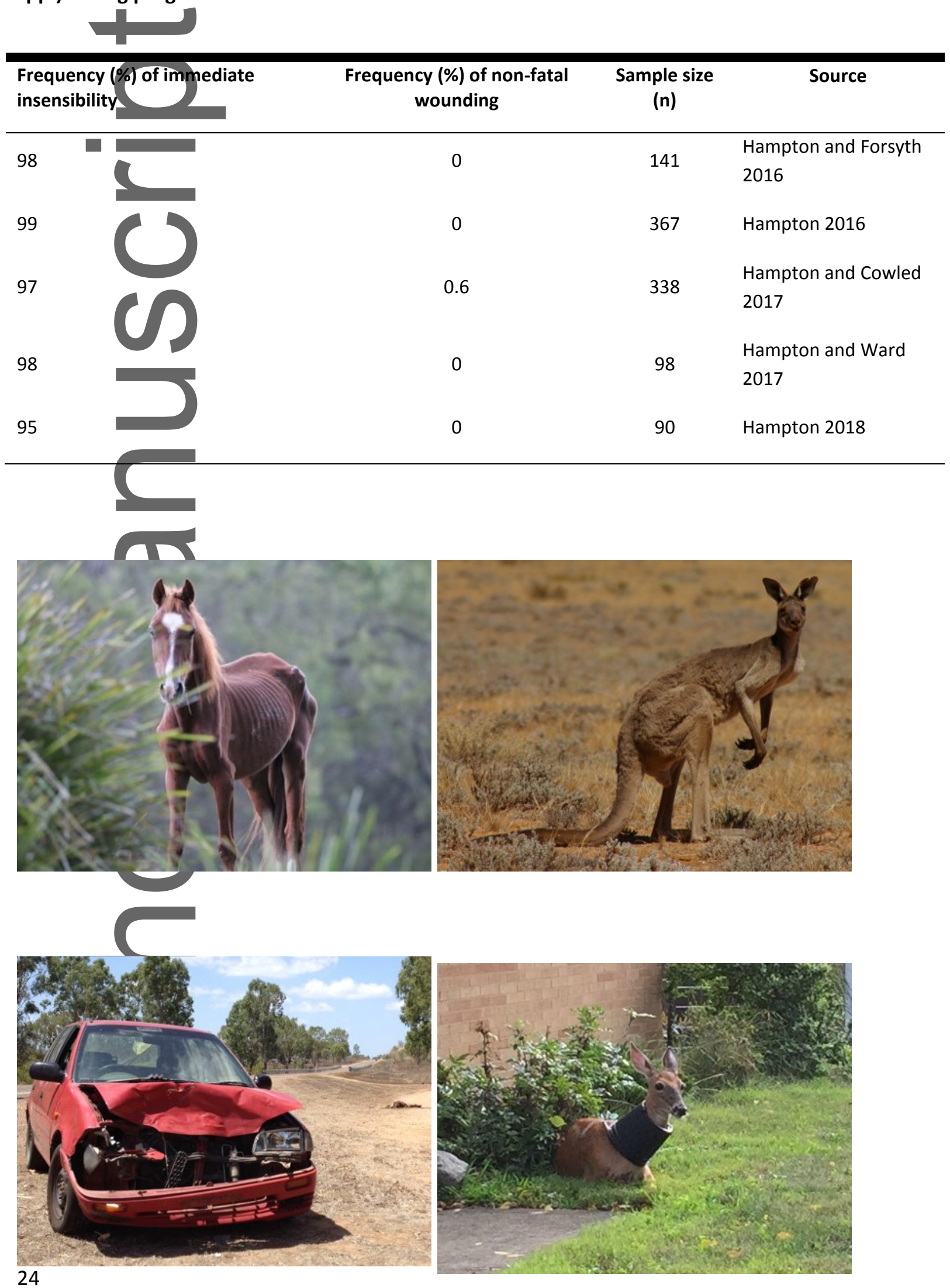

This article is protected by copyright. All rights reserved. 


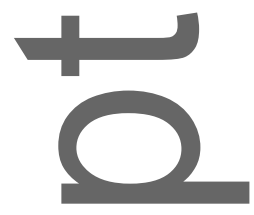

Figure 1. Examples of unintentional animal welfare impacts arising from failure to reduce population density in overabundant wild herbivores: an emaciated wild horse (Equus caballus; top left; photo by A. Harvey), an emaciated western grey kangaroo (Macropus fulginosus; top right; photo by G. Coulson), a vehicle collision with an axis deer (Axis axis; bottom left; photo by J. Hampton), and an entangled urban white-tailed deer (Odocoileus virginianus; bottom right; photo by T. Dryja).

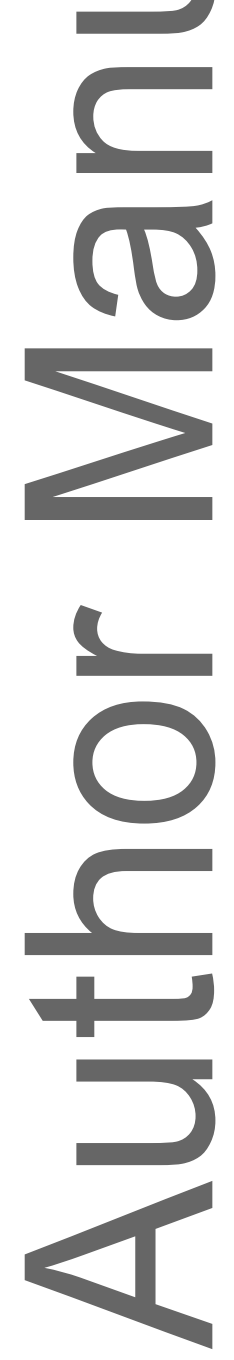

This article is protected by copyright. All rights reserved. 


\section{University Library}

\section{- M M I E E R VA A gateway to Melbourne's research publications}

Minerva Access is the Institutional Repository of The University of Melbourne

\section{Author/s:}

Hampton, JO;Warburton, B;Sandoe, $\mathrm{P}$

Title:

Compassionate versus consequentialist conservation

Date:

2019-08-01

Citation:

Hampton, J. O., Warburton, B. \& Sandoe, P. (2019). Compassionate versus consequentialist conservation. CONSERVATION BIOLOGY, 33 (4), pp.751-759. https://doi.org/10.1111/ cobi.13249.

Persistent Link:

http://hdl.handle.net/11343/285244 